\title{
JAPONESES EM PRESIDENTE PRUDENTE: RELAÇÕES COM O ESTADO E A SOCIEDADE PRUDENTINA DURANTE O ESTADO NOVO E NO IMEDIATO PÓS-GUERRA ATÉ 1947
}

José Libório Vilione

Professor Especialista da FAPREV (Faculdade de Presidente Venceslau). E-mail: vilione@bol.com.br; jlviliione@gmail.com

\section{RESUMO}

O objetivo deste trabalho é discutir as relações políticas, econômicas e sociais da colônia japonesa com o Estado e a sociedade em Presidente Prudente, no período do Estado Novo e no imediato pós-guerra, até 1947. Sua contribuição para o desenvolvimento econômico da região, bem como, às dificuldades encontradas na assimilação da cultura ocidental. Os conflitos no interior da colônia aflorados pelas atitudes antagônicas entre seus membros, ou seja, a tentativa da manutenção cultural nipônica pelos mais velhos contra o desejo ou necessidade de assimilar a cultura ocidental (brasileira) pelos mais novos. Verificar e constatar as relações mais amenas entre os japoneses com o Estado e a sociedade local, contrariando as determinações governamentais superiores, principalmente a partir do momento em que o Brasil entra na 2a Guerra Mundial. Identificar os principais motivos que contribuíram para os conflitos no interior da colônia no período da 2a Guerra Mundial.

Palavras-chave: Colônia japonesa. Relações. Estado Novo.

\section{INTRODUÇÃO E OBJETIVO}

O objetivo deste trabalho é discutir as relações políticas, econômicas e sociais da colônia japonesa com o Estado e a sociedade em Presidente Prudente, no período do Estado Novo e no imediato pós-guerra, até 1947, destacando a história da chegada dos primeiros imigrantes no Brasil e na região da Alta Sorocabana, assim como as atividades em que foram empregados. Para isto, utilizamos relatos sobre o movimento migratório, a história da colônia japonesa e de seus integrantes, como, também, reflexões sobre as instituições educacionais e culturais criadas, e sobre os fatos que influenciavam a ordem pública (políticos, econômicos e sociais) em Presidente Prudente naquele período.

O presente estudo visa identificar em que grau as relações políticas, econômicas e sociais da colônia japonesa com o Estado e a sociedade em Presidente Prudente influenciaram na sociedade prudentina. Identificar quais as maneiras que os japoneses utilizaram para se aproximarem da sociedade prudentina; analisar as iniciativas e instrumentos que a colônia japonesa utilizou para a manutenção da sua cultura na região; discutir e apresentar um histórico sobre a formação da colônia em Presidente Prudente e sua trajetória entre o período de 19371947. 


\section{METODOLOGIA}

Para este trabalho, foi determinado um recorte no período de 1937-1947, porém foram realizados levantamentos desde a chegada dos primeiros imigrantes japoneses das Vilas Goulart/Marcondes para que possamos entender a história da colônia japonesa no município de Presidente Prudente.

A pesquisa foi exploratória de documentos oficiais nas esferas dos três poderes e de governos, ou seja, Federal, Estadual e Municipal, bem como, de documentos particulares do Dr. Domingos Leonardo Cerávolo. Pesquisaram-se ações dos japoneses em diversas fontes, documentos oficiais dos três poderes do Estado (Executivo, Legislativo e Judiciário), da colônia japonesa, da Delegacia Regional de Polícia de Presidente Prudente, bibliografias, fontes jornalísticas, fotos, sendo utilizado o método histórico de investigação.

\section{RESULTADOS}

Verificado em bibliografias que as relações dos japoneses com o Estado de um modo geral não foram harmoniosas, principalmente com a implantação do Estado nacionalista por Getúlio Vargas. Foram criadas leis limitando a entrada de estrangeiros. Dificultando a situação dos estrangeiros empregados em empresas. Outras leis limitando as atividades culturais, jogando na clandestinidade escolas e associações culturais desses estrangeiros. Porém, verificamos que na região de Presidente Prudente essas relações foram mais amenas, na medida do possível. Constatamos que as relações da colônia japonesa, como também, de instituições de japoneses ou mesmo individuais eram harmoniosas com o Estado e a sociedade na região de Presidente Prudente, principalmente nas atividades econômicas, contrariando o que ocorria em outras regiões do Estado de São Paulo ou mesmo em outras regiões do país.

\section{DISCUSSÃO}

O destino dos primeiros imigrantes japoneses até 1930 foi majoritariamente no Estado de São Paulo com o objetivo de trabalharem nas fazendas de café do Oeste Paulista, com um índice considerável na região de Presidente Prudente. ${ }^{1}$

\footnotetext{
${ }^{1}$ LEITE, José Ferrari. A alta sorocabana e o espaço polarizado de Presidente Prudente. Presidente Prudente: Faculdade de Filosofia, Ciências e Letras de Presidente Prudente, 1972, p. 33; o autor baseia-se em comparação demográfica entre negros e amarelos; MORAIS, Fernando. Corações sujos. São Paulo: Companhia das Letras, 2000, p. 25; HANDA, Tomoo. Memórias de um imigrante japonês no Brasil. Trad. Antonio Nojiri. São Paulo: Centro de Estudos Nipo-Brasileiro, 1980, p. 18, 84-86; ONO, Morio. De colono a pequeno produtor: considerações sobre a agricultura japonesa. In: SAITO, Hiroshi. Assimilação e integração dos japoneses no Brasil. Petrópolis: Vozes; São Paulo: Ed. da Universidade de São Paulo, 1973, p. 133; SAITO, Hiroshi. Mobilidade e assimilação de imigrantes japoneses. In: SAITO, Hiroshi. Assimilação e integração dos japoneses no Brasil. Petrópolis: Vozes; São Paulo: Ed. da Universidade de São Paulo, 1973, p. 468.
} 
A Chegada no Porto de Santos das primeiras famílias japonesas em 1908 no navio Kasato Maru na noite de 17 de junho, porém, aportaram somente no amanhecer do dia $18 .^{2}$ Mesmo com todas as dificuldades que os primeiros encontraram, continuaram desembarcando no porto de Santos outros imigrantes japoneses, atingindo no Brasil em 1940 uma população de aproximadamente 164 mil. $^{3}$ Devemos deixar claro que nem todos foram para a área rural. ${ }^{4}$

A partir do governo nacionalista instalado por Getúlio Vargas em 1930, surgiram leis que potencializaram as dificuldades dos estrangeiros no Brasil. ${ }^{5}$

Com a eclosão da 2a Guerra Mundial a pressão sobre os estrangeiros aumentou, principalmente aos "súditos do eixo", porém, entre as etnias que mais sofreram está à nipônica, ${ }^{6}$ que já vinha sofrendo segregação no combate aos "quistos étnicos". 7

Na região da Alta Sorocabana, em Presidente Prudente, chegaram os primeiros imigrantes em 1918, adquiriram terras na região. Um detalhe, os respectivos chefes de família já estavam na região sem suas famílias, pois eram operários na construção da Estrada de Ferro Sorocabana

\footnotetext{
${ }^{2}$ HANDA, Tomoo. Memórias de um imigrante japonês no Brasil. Trad. Antonio Nojiri. São Paulo: Centro de Estudos Nipo-Brasileiro, 1980 , p. 3-5. ${ }^{3}$ MORAIS, Fernando. Corações sujos. São Paulo: Companhia das Letras, 2000, p. 30; CARDOSO, Ruth C. L. Estrutura familiar e mobilidade social: estudo dos japoneses no Estado de São Paulo. São Paulo: Kaleidos-Primus Consultoria e Comunicação Integrada S/C Ltda., 1998, p. 18.

${ }^{4}$ TANNO, Janete Leiko. Formas de sociabilidade e inserção de imigrantes japoneses e seus descendentes na sociedade paulista. 1930-1970. In: HASHIMOTO, Francisco; TANNO, Janete Leiko; OKAMOTO, Mônica Setuyo (Org.). Cem anos da imigração japonesa: história, memória e arte. São Paulo: Editora UNESP, 2008, p. 68, 72.

${ }^{5}$ Decreto no 19.482/30; KUMASACA, Y; SAITO, H. Kachigumi: uma delusão coletiva entre os japoneses e seus descendentes no Brasil. In: SAITO, Hiroshi. Assimilação e integração dos japoneses no Brasil. Petrópolis: Vozes; São Paulo: Ed. da Universidade de São Paulo, 1973, p. 451 e 452; GERALDO, Endrica. Trabalhadores estrangeiros em tempos de guerra. Revista PERSEU, São Paulo: Agosto, n. 2, agosto 2008, p. 181, 186 e 192-193. Disponível em: <www.fpabramo.org.br/uploads/P2AEndricaGeraldo.pdf>. Acesso em: 05 mai. 2013; GERALDO, Endrica. 0 combate contra os "quistos étnicos": identidade, assimilação e política imigratória no Estado Novo. Locus: revista de história, Juiz de Fora: jan-jun, set. 2009, v.1 5, n. 1, p. 172 e 179. Disponível em: <http://www.ufjf.br/locus/edicoes-anteriores/volume-15-numero-2-2009/>. Acesso em 06 mai. 2013; Constituição Federal de 1934: Art 121; HANDA, Tomoo. Memórias de um imigrante japonês no Brasil. Trad. Antonio Nojiri. São Paulo: Centro de Estudos NipoBrasileiro, 1980, p. 107; IZUMI, Seiichi. A estrutura psicológica da colônia japonesa no Brasil In: SAITO, Hiroshi. Assimilação e integração dos japoneses no Brasil. Petrópolis: Vozes; São Paulo: Ed. da Universidade de São Paulo, 1973, p. 37 e 379; MAEYAMA, Takazhi. 0 antepassado, o imperador e o imigrante: religião de identificação de grupo dos japoneses no Brasil Rural. In: SAITO, Hiroshi. Assimilação e integração dos japoneses no Brasil. Petrópolis: Vozes; São Paulo: Ed. da Universidade de São Paulo, 1973, p. 439, 440-442; SILVA, Zélia Lopes da. Imigração e cidadania: os impasses e disputas nos caminhos da brasilidade. In: HASHIMOTO, Francisco; TANNO, Janete Leiko; OKAMOTO, Mônica Setuyo (Org.). Cem anos da imigração japonesa: história, memória e arte. São Paulo: Editora UNESP, 2008, p. 58-59; SANTOS, Valdery. Pioneiros da imigração japonesa na Alta Sorocabana. [s.n.], Presidente Prudente, 2001, p. 37, 50; Alguns decretos da legislação sobre os imigrantes: Decreto no 2.265/38; Decreto-lei $n$ o 4.638; Decreto-Lei no 383/38; Decreto-lei no 406/38; Decreto-lei no 639/38; Decreto-lei no 809/38; Decreto-lei no 868/38; Decreto-lei no 948/38; Decreto-lei no 3.010/38; Decreto-lei no 3.016/38; "Relatório da viagem às zonas desnacionalizadas - Relatório da viagem à Fazenda Bastos, núcleo de colonização nipônica, e ao Vale do Itajaí, zona de colonização germânica, pelos membros do C.I.C. - Aristóteles de Lima Câmara e Artur Hehl Neiva, em janeiro de 1940", p. 65-66. AHN - CPDOC/FGV.; CRUZ, Elmano. Direitos e deveres dos súditos do Eixo: doutrina, legislação, jurisprudência. Rio de Janeiro: Nacional de Direito, 1944 apud GERALDO, Endrica. Trabalhadores estrangeiros em tempos de guerra. Revista PERSEU, São Paulo: Agosto, n. 2, agosto 2008, p. 192-193 e 197; Disponível em: <www.fpabramo.org.br/uploads/P2AEndricaGeraldo.pdf>. Acesso em: 05 mai. 2013.

${ }^{6}$ CYTRYNOWICZ, Roney. Guerra sem guerra: a mobilização e o cotidiano em São Paulo durante a Segunda Guerra Mundial. São Paulo: Geração Editorial/Edusp, 2000, p. 18-19, 139.

7 GERALDO, Endrica. O combate contra os "quistos étnicos": identidade, assimilação e política imigratória no Estado Novo. Locus: revista de história, Juiz de Fora: jan-jun, set. 2009, v.1 5, n. 1, p. 185-186. Disponível em: <http://www.ufjf.br/locus/edicoes-anteriores/volume-15-numero-22009/>. Acesso em 06 mai. 2013; GERALDO, Endrica. Trabalhadores estrangeiros em tempos de guerra. Revista PERSEU, São Paulo: Agosto, n. 2, agosto 2008, p. 191-192. Disponível em: <www.fpabramo.org.br/uploads/P2AEndricaGeraldo.pdf>. Acesso em: 05 mai. 2013; KUMASACA, Y; SAITO, H. Kachigumi: uma delusão coletiva entre os japoneses e seus descendentes no Brasil. In: SAITO, Hiroshi. Assimilação e integração dos japoneses no Brasil. Petrópolis: Vozes; São Paulo: Ed. da Universidade de São Paulo, 1973, p. 452; IZUMI, Seiichi. A estrutura psicológica da colônia japonesa no Brasil In: SAITO, Hiroshi. Assimilação e integração dos japoneses no Brasil. Petrópolis: Vozes; São Paulo: Ed. da Universidade de São Paulo, 1973, p. 379; MORAIS, Fernando. Corações sujos. São Paulo: Companhia das Letras, 2000, p. 45-51; SANTOS, Valdery. Pioneiros da imigração japonesa na Alta Sorocabana. [s.n.], Presidente Prudente, 2001, p. 36-37; na região de Presidente Prudente o confisco dos bens móveis consta em documentos da Delegacia Regional de Polícia de Presidente Prudente que estão no Museu e Arquivo Histórico Prefeito Sandoval Neto de Presidente Prudente.
} 
desde 1913. Em 1919, outros se estabelecendo como comerciante. No ano seguinte, com o objetivo de serem arrendatários. ${ }^{8}$

Com o intuito de preservar a cultura e suas origens, os japoneses começam a criar associações para a prática de seus costumes e religião, ${ }^{9}$ assim em 1920, como em outras regiões, inicia-se a colonização de um bairro japonês denominado Sankyô. Outros bairros japoneses foram criados, como o Sankiyo Shokuminchi, no Distrito de Montalvão. É fundada a Associação Japonesa Unida de Presidente Prudente "Rengo Nipponjinkai", em 1929, posteriormente mudando seu nome para Associação Cultural Agrícola Esportiva de Presidente Prudente (ACAE). É criado o Colégio São Paulo, oferecendo o curso ginasial e o primeiro curso secundário da região. ${ }^{10}$

Posteriormente, outros imigrantes japoneses chegaram à região empenhados em várias atividades econômicas e, segundo José Ferrari, tiveram importante participação na organização regional, ${ }^{11}$ destacando-se na atividade rural, influenciando na transformação da agricultura regional. ${ }^{12}$ Os imigrantes trabalharam, não exclusivamente, nas lavouras de café e algodão, mas se dedicaram a outras culturas agrícolas, ${ }^{13}$ entre essas à produção olerícola, sendo que $90 \%$ da produção do Estado de São Paulo era realizada pelos japoneses. ${ }^{14}$

A produção da hortelã e da seda animal foi motivo de conflitos entre os japoneses no período da 2a Guerra Mundial, pois, segundo os japoneses denominados tenchugumi, a hortelã era matéria-prima na produção do mentol utilizado na indústria de guerra dos aliados e a seda animal era utilizada na confecção dos pára-quedas dos aliados, ${ }^{15}$ portanto, os japoneses produtores de hortelã e seda animal, eram considerados "traidores da pátria". ${ }^{16}$ A região de Presidente Prudente não ficou fora desse cenário, pois era grande produtora de hortelã, potencializada pela 2a Guerra Mundial, como mencionou José Carlos Ferrari: “A cultura de menta

\footnotetext{
${ }^{8}$ SANTOS, Valdery. Pioneiros da imigração japonesa na Alta Sorocabana. [s.n.], Presidente Prudente, 2001, p. 56-60, 73-83, 87-88; SHICASHO, Emika Tanaka (Coord). A saga dos imigrantes japoneses em Presidente Prudente. [s.n.t.], p. 33-34.

${ }^{9}$ TANNO, Janete Leiko. Formas de sociabilidade e inserção de imigrantes japoneses e seus descendentes na sociedade paulista. 1930-1970. In: HASHIMOTO, Francisco; TANNO, Janete Leiko; OKAMOTO, Mônica Setuyo (Org.). Cem anos da imigração japonesa: história, memória e arte. São Paulo: Editora UNESP, 2008, p. 73; GERALDO, Endrica. O combate contra os "quistos étnicos": identidade, assimilação e política imigratória no Estado Novo. Locus: revista de história, Juiz de Fora: jan-jun, set. 2009, v.1 5, n. 1, p. 174. Disponível em: <http://www.ufjf.br/locus/edicoesanteriores/volume-15-numero-2-2009/>. Acesso em 06 mai. 2013.

${ }^{10}$ SANTOS, Valdery. Pioneiros da imigração japonesa na Alta Sorocabana. [s.n.], Presidente Prudente, 2001, p. 49-53; SHICASHO, Emika Tanaka (Coord). A saga dos imigrantes japoneses em Presidente Prudente. [s.n.t.], p. 37-38.

${ }^{11}$ LEITE, José Ferrari. A alta sorocabana e o espaço polarizado de Presidente Prudente. Presidente Prudente: Faculdade de Filosofia, Ciências e Letras de Presidente Prudente, 1972, p. 57.

${ }^{12}$ Ibidem, p. 58.

${ }^{13}$ Ibidem, p. 33.

${ }^{14}$ ONO, Morio. De colono a pequeno produtor: considerações sobre a agricultura japonesa. In: SAITO, Hiroshi. Assimilação e integração dos japoneses no Brasil. Petrópolis: Vozes; São Paulo: Ed. da Universidade de São Paulo, 1973, p. 141.

${ }^{15}$ MORAIS, Fernando. Corações sujos. São Paulo: Companhia das Letras, 2000, p. 65; KUMASACA, Y; SAITO, H. Kachigumi: uma delusão coletiva entre os japoneses e seus descendentes no Brasil. In: SAITO, Hiroshi. Assimilação e integração dos japoneses no Brasil. Petrópolis: Vozes; São Paulo: Ed. da Universidade de São Paulo, 1973, p. 453.

${ }^{16}$ MORAIS, Fernando. Corações sujos. São Paulo: Companhia das Letras, 2000, p. 65-66; KUMASACA, Y; SAITO, H. Kachigumi: uma delusão coletiva entre os japoneses e seus descendentes no Brasil. In: SAITO, Hiroshi. Assimilação e integração dos japoneses no Brasil. Petrópolis: Vozes; São Paulo: Ed. da Universidade de São Paulo, 1973, p. 453; CARDOSO, Ruth C. L. Estrutura familiar e mobilidade social: estudo dos japoneses no Estado de São Paulo. São Paulo: Kaleidos-Primus Consultoria e Comunicação Integrada S/C Ltda., 1998, p. 51-52.
} 
enriqueceu a muitos durante a guerra, atraindo pessoas e capital de várias camadas sociais para o campo", colaborando com a instalação de Indústrias de mentol em Presidente Prudente, o autor ainda menciona que a menta foi introduzida no Brasil justamente na Alta Sorocabana por japoneses. ${ }^{17}$ Nas palavras de Díores Santos Abreu: "A estatística de produção aponta como importante à sericicultura em Presidente Prudente, na década de 30, e há notícias da sua presença na década anterior". ${ }^{18}$

Os conflitos estão registrados no jornal "A Voz do Povo", nos documentos da DRP de Presidente Prudente, no arquivo do Poder Judiciário do Estado de São Paulo.

As relações entre japoneses e brasileiros na região de Presidente Prudente às vezes eram harmoniosas $^{19}$ e em outras vezes não tanto.

Verificamos momentos em que o relacionamento do Dr. Cerávolo como prefeito (interventor) com os japoneses era bem íntimo, seja diretamente ou como representantes de instituições. Documentos oficiais (1942-1943) demonstram esse bom relacionamento da Prefeitura com a Instituição Educacional Colégio São Paulo, ${ }^{20}$ contrariando as determinações governamentais superiores. ${ }^{21}$ Nesse mesmo sentido, uma portaria nomeando um nissei para o cargo de Inspetor de Estradas e Rodagem para o Distrito de Álvares Machado, na época pertencente ao município de Presidente Prudente (1943). Um ofício municipal dirigido ao Diretor de Departamento de Geografia, Terras e Colonização do Estado do Paraná, recomendando alguns japoneses para que adquirissem terras no Estado (1946). Por fim, outro documento firmado pelo prefeito sugere que o Departamento de Ordem Política e Social (DOPS) seja benevolente com os "súditos japoneses" (1946).

Outros documentos de cunho particular do Dr. Cerávolo explicitam as boas relações que mantinha com a colônia japonesa, fossem esses estrangeiros parceiros econômicos ou mesmo empregados, uma vez que Cerávolo, além de prefeito e médico, era latifundiário na região, empregando muitos japoneses em suas lavouras, com destaque para a produção de hortelã. ${ }^{22}$

\footnotetext{
${ }^{17}$ ABREU, Dióres Santos. Poder político local do populismo: Presidente Prudente (SP) 1928-1959. Presidente Prudente: Impress, 1996, p. 63; LEITE, José Ferrari. A alta sorocabana e o espaço polarizado de Presidente Prudente. Presidente Prudente: Faculdade de Filosofia, Ciências e Letras de Presidente Prudente, 1972, p. 61,66-68, 71; SANTOS, Valdery. Pioneiros da imigração japonesa na Alta Sorocabana. [s.n.], Presidente Prudente, 2001, p. 87-88; RESENDE, Benjamim. Raízes prudentinas II. Presidente Prudente: Ed. do autor, 2006, p. 53-54.

${ }^{18}$ ABREU, Dióres Santos. A formação histórica de uma cidade pioneira paulista: Presidente Prudente. Presidente Prudente: UNESP, 1972, p. 126, 131; o incremento da produção da seda animal é amplamente divulgado pela impressa escrita local: os jornais "A Voz do Povo" e "O Imparcial"

${ }^{19}$ RESENDE, Benjamim. Raízes prudentinas II. Presidente Prudente: Ed. do autor, 2006, p. 91-92.

${ }^{20} \mathrm{O}$ Colégio São Paulo pertencia à Colônia Japonesa. O estreito relacionamento do prefeito Cerávolo com o Colégio São Paulo foi motivo de uma advertência ao prefeito por parte do próprio Vargas; SANTOS, Valdery. Pioneiros da imigração japonesa na Alta Sorocabana. [s.n.], Presidente Prudente, 2001, p. 50-51.

${ }^{21}$ Circular do diretor geral do Departamento das Municipalidades determinando as comemorações do $2^{\circ}$ aniversário do rompimento das relações diplomáticas do Brasil com os paises do "eixo".

${ }^{22}$ Entre os documentos existem relações de pagamento, nota-se que os japoneses recebem bem mais que outros funcionários, infelizmente não podemos fazer, até presente momento, qualquer afirmação sobre os motivos desses percentuais diferentes, pois demandaria uma pesquisa mais minuciosa e complexa.
} 
Documentos da DRP, também nos fornece uma indicação do bom relacionamento dos japoneses com o Estado em Presidente Prudente. Nesse sentido, vários ofícios solicitando o pagamento por serviços prestados de empresas pertencentes a japoneses (1945-1946).

Outros levantamentos em fontes jornalísticas dão a dimensão do relacionamento dos japoneses com as forças políticas e sociais de Presidente Prudente e região (economia e cultura).

\section{CONCLUSÃO}

O exposto acima, nos dá uma pequena amostra das diferenças nas relações dos japoneses com o Estado e a sociedade em diferentes níveis de poder, ou seja, nacional, estadual e regional.

As informações obtidas até o momento nos dão uma indicação de que essas relações não são homogenias em todo território nacional, nem mesmo estadual ou regional. O que nos dá essa indicação? Quando nos deparamos com as fontes de amplitude nacional e estadual elas nos mostram um tratamento mais rígido aos estrangeiros, principalmente aos "súditos do eixo", porém nas fontes regionais ${ }^{23}$ o tratamento é mais ameno, isso ficou bem explícito, principalmente quando mencionamos as relações que o Dr. Domingos Leonardo Cerávolo tinha com os japoneses.

Portanto, para que tenhamos mais informações que nos possibilite maiores e melhores conclusões, será necessária a composição de outro trabalho com um formato mais complexo.

\section{REFERÊNCIAS}

ABREU, Dióres Santos. A formação histórica de uma cidade pioneira paulista: Presidente Prudente. Presidente Prudente: UNESP, 1972.

ABREU, Dióres Santos. Poder político local do populismo: Presidente Prudente (SP) 1928-1959. Presidente Prudente: Impress, 1996.

CARDOSO, Ruth C. L. Estrutura familiar e mobilidade social: estudo dos japoneses no Estado de São Paulo. São Paulo: Kaleidos-Primus Consultoria e Comunicação Integrada S/C Ltda., 1998.

CYTRYNOWICZ, Roney. Guerra sem guerra: a mobilização e o cotidiano em São Paulo durante a Segunda Guerra Mundial. São Paulo: Geração Editorial/Edusp, 2000.

GERALDO, Endrica. Trabalhadores estrangeiros em tempos de guerra. Revista PERSEU, São Paulo: Agosto, $\quad$ n. 2, $2008 . \quad$ Disponível em: <www.fpabramo.org.br/uploads/P2AEndricaGeraldo.pdf>. Acesso em: 05 mai. 2013.

GERALDO, Endrica. O combate contra os "quistos étnicos": identidade, assimilação e política imigratória no Estado Novo. Locus: revista de história, Juiz de Fora: jan-jun, set. 2009, v.1 5, n. 1.

\footnotetext{
${ }^{23}$ Tratando-se da Região de Presidente Prudente, ou seja, não estamos falando de toda a Região da Alta Sorocabana.
} 
Disponível em: <http://www.ufjf.br/locus/edicoes-anteriores/volume-15-numero-2-2009/>. Acesso em 06 mai. 2013.

HANDA, Tomoo. Memórias de um imigrante japonês no Brasil. Trad. Antonio Nojiri. São Paulo: Centro de Estudos Nipo-Brasileiro, 1980.

IZUMI, Seiichi. A estrutura psicológica da colônia japonesa no Brasil In: SAITO, Hiroshi. Assimilação e integração dos japoneses no Brasil. Petrópolis: Vozes; São Paulo: Ed. da Universidade de São Paulo, 1973.

KUMASACA, Y; SAITO, H. Kachigumi: uma delusão coletiva entre os japoneses e seus descendentes no Brasil. In: SAITO, Hiroshi. Assimilação e integração dos japoneses no Brasil. Petrópolis: Vozes; São Paulo: Ed. da Universidade de São Paulo, 1973.

LEITE, José Ferrari. A alta sorocabana e o espaço polarizado de Presidente Prudente. Presidente Prudente: Faculdade de Filosofia, Ciências e Letras de Presidente Prudente, 1972.

MAEYAMA, Takazhi. $\mathbf{O}$ antepassado, o imperador e o imigrante: religião de identificação de grupo dos japoneses no Brasil Rural. In: SAITO, Hiroshi. Assimilação e integração dos japoneses no Brasil. Petrópolis: Vozes; São Paulo: Ed. da Universidade de São Paulo, 1973.

MORAIS, Fernando. Corações sujos. São Paulo: Companhia das Letras, 2000.

ONO, Morio. De colono a pequeno produtor: considerações sobre a agricultura japonesa. In: SAITO, Hiroshi. Assimilação e integração dos japoneses no Brasil. Petrópolis: Vozes; São Paulo: Ed. da Universidade de São Paulo, 1973.

RESENDE, Benjamim. Raízes prudentinas II. Presidente Prudente: Ed. do autor, 2006.

SAITO, Hiroshi. Mobilidade e assimilação de imigrantes japoneses. In: SAITO, Hiroshi. Assimilação e integração dos japoneses no Brasil. Petrópolis: Vozes; São Paulo: Ed. da Universidade de São Paulo, 1973.

SANTOS, Valdery. Pioneiros da imigração japonesa na Alta Sorocabana. [s.n.], Presidente Prudente, 2001.

SHICASHO, Emika Tanaka (Coord). A saga dos imigrantes japoneses em Presidente Prudente. [s.n.t.].

SILVA, Zélia Lopes da. Imigração e cidadania: os impasses e disputas nos caminhos da brasilidade. In: HASHIMOTO, Francisco; TANNO, Janete Leiko; OKAMOTO, Mônica Setuyo (Org.). Cem anos da imigração japonesa: história, memória e arte. São Paulo: Editora UNESP, 2008.

TANNO, Janete Leiko. Formas de sociabilidade e inserção de imigrantes japoneses e seus descendentes na sociedade paulista. 1930-1970. In: HASHIMOTO, Francisco; TANNO, Janete Leiko; OKAMOTO, Mônica Setuyo (Org.). Cem anos da imigração japonesa: história, memória e arte. São Paulo: Editora UNESP, 2008. 